Pacific Journal of Mathematics

CAPACITIES OF COMPACT SETS IN LINEAR SUBSPACES OF 


\title{
CAPACITIES OF COMPACT SETS IN LINEAR SUBSPACES OF $R^{n}$
}

\author{
TORD SJöDIN
}

\begin{abstract}
We consider two types of spaces, the Bessel potential spaces $L_{\alpha}^{p}\left(R^{n}\right)$ and the Besor spaces $\Lambda_{\alpha}^{p}\left(R^{n}\right), \alpha>0,1<p<\infty$. Associated in a natural way with these spaces are classes of exceptional sets. We characterize the exceptional sets for $\Lambda_{\alpha}^{p}\left(R^{n}\right)$ by an extension property for continuous functions and prove an inequality between Bessel and Besov capacities.
\end{abstract}

The classes of exceptional sets for the spaces $L_{\alpha}^{p}\left(R^{n}\right)$ have been studied by the concept of capacity [5]. Capacity definitions of these classes are given in $\S 2$.

Bessel potential spaces and Besov spaces in $R^{n}$ and $R^{n+1}$ are connected by restriction theorems. A short statement of these results is the following:

$$
\begin{gathered}
\left.L_{\beta}^{p}\left(R^{n+1}\right)\right|_{R^{n}}=\Lambda_{\alpha}^{p}\left(R^{n}\right) \\
\left.\Lambda_{\beta}^{p}\left(R^{n+1}\right)\right|_{R^{n}}=\Lambda_{\alpha}^{p}\left(R^{n}\right),
\end{gathered}
$$

where $\alpha>0,1<p<\infty$, and $\beta=\alpha+1 / p$. (0. V. Besov [4] and E.M. Stein [7].)

The restriction theorem above gives relations between exceptional classes of different spaces $L_{\alpha}^{p}$ and $\Lambda_{\alpha}^{p}$ in $R^{n}$ and $R^{n+1}$.

This enables us to prove an extension theorem for continuous functions on a compact set $K \subset R^{n}$ into $\Lambda_{\alpha}^{p}\left(R^{n}\right)$ (Theorem 1) analogous to the $L_{\alpha}^{p}\left(R^{n}\right)$ - case contained in [6, Theorem 1]. Finally we prove an inequality between the capacities defining the classes of exceptional sets for $\Lambda_{\alpha}^{p}\left(R^{n}\right)$ and $L_{\alpha}^{p}\left(R^{n}\right)$ (Theorem 2).

2. Preliminaries and statements of the theorems, We consider the $n$-dimensional space $R^{n}$ of $n$-tuples $x=\left(x_{1}, x_{2}, \cdots, x_{n}\right)$. Points in $R^{n+1}$ are written $\left(x, x_{n+1}\right)$, where $x \in R^{n}$ and $x_{n+1} \in R^{1}$. Then $R^{n}$ is identified as the subspace $\left\{(x, 0) ; x \in R^{n}\right\}$ of $R^{n+1}$. Compact sets are denoted by $K$. If $K \subset R^{n}$ then $K$ is a compact subset of $R^{n+1}$ as well. As usual, the space of $p$-summable functions is denoted by $L^{p}\left(R^{n}\right)$ with norm $\|\cdot\|_{p}$. The Bessel kernel $G_{\alpha}^{n}$ in $R^{n}$ is the $L^{1}\left(R^{n}\right)$ function whose Fourier transform equals $\left(1+|x|^{2}\right)^{-\alpha / 2}, \alpha>0$.

The space of convolutions $U=G_{\alpha}^{n} * f$, where $f \in L^{p}\left(R^{n}\right)$, with the norm $\|U\|_{\alpha, p}=\|f\|_{p}$, is denoted by $L_{\alpha}^{p}\left(R^{n}\right), \alpha>0,1 \leqq p<\infty$. A function $U \in \Lambda_{\alpha}^{p}\left(R^{n}\right), 1 \leqq p \leqq \infty, 0<\alpha<1$ if

$$
|U|_{\alpha, p}=\|U\|_{p}+\left(\iint \frac{|U(x)-U(y)|^{p}}{|x-y|^{a p+n}} d x d y\right)^{1 / p}
$$


is finite. (When no limits of integration are indicated it is understood that the integration is over the whole space.)

When $1 \leqq \alpha<2$ we replace the first difference by the second difference. Finally, for $\alpha \geqq 2, U \in \Lambda_{\alpha}^{p}\left(R^{n}\right)$ if and only if $U \in L^{p}$ and $\partial U / \partial x_{i} \in \Lambda_{\alpha-1}^{p}\left(R^{n}\right), 1 \leqq i \leqq n$, with the norm

$$
|U|_{\alpha, p}=\|U\|_{p}+\sum_{i=1}^{n}\left|\frac{\partial U}{\partial x_{i}}\right|_{\alpha-1, p} .
$$

We consider the following two capacities for compact sets $K \subset R^{n}$, $\alpha>0,1<p<\infty$.

$$
\begin{aligned}
& A_{\alpha, p}^{n}(K)=\inf |\varphi|_{\alpha, p}^{p}, \\
& B_{\alpha, p}^{n}(K)=\inf \|\varphi\|_{\alpha, p}^{p},
\end{aligned}
$$

where, in both cases, the infimum is taken over all $\varphi \in C_{0}^{\infty}\left(R^{n}\right)$ such that $\varphi(x) \geqq 1$ for every $x \in K$. $C_{0}^{\infty}\left(R^{n}\right)$ is the infinitely differentiable functions on $R^{n}$ with compact support.

The $B_{\alpha, p}^{n}$-capacity has several equivalent definitions $[2,5]$. We mention that

$$
B_{\alpha, p}^{n}(K)=\inf \|f\|_{p}^{p}
$$

where infimum is over $f \in L_{+}^{p}$ such that $G_{\alpha}^{n} * f(x) \geqq 1$ on $K$. (A lower superscript + indicates positive elements.) The sign $\sim$ means that the ratio is bounded from below and above by positive real numbers. Further, $B_{\alpha, p}^{n}(K)=\left(\sup \|\mu\|_{1}\right)^{p}$ where supremum is over positive Borel measures $\mu$ concentrated on $K$ with total variation $\|\mu\|_{1}<\infty$ and $\left\|G_{\alpha}^{n} * \mu\right\|_{q} \leqq 1$.

Here $q=p / p-1$. See [5] where this capacity is denoted by $b_{\alpha, p}$. Let $K$ be a compact subset of $R^{n}$. We have proved that $B_{\alpha, p}^{n}(K)=0$ if and only if every continuous function on $K$ is the restriction to $K$ of a continuous function in $L_{\alpha}^{p}\left(R^{n}\right)$ [6, Theorem 1]. We prove here the analogue for $\Lambda_{\alpha}^{p}\left(R^{n}\right)$. Let $C(E)$ denote the space of continuous functions on a set $E$ in $R^{n}$.

THEOREM 1. Let $1<p<\infty, 0<\alpha \cdot p \leqq n$ and let $K$ be a compact subset of $R^{n}$. Then $A_{\alpha, p}^{n}(K)=0$ if and only if every function $f_{0} \in C(K)$ has an extension $f \in \Lambda_{\alpha}^{p}\left(R^{n}\right) \cap C\left(R^{n}\right)$.

When $\alpha p>n$, the capacities $A_{\alpha, p}^{n}$ and $B_{\alpha, p}^{n}$ are positive unless $K$ is empty [3].

We denote the exceptional classes for $L_{\alpha}^{p}\left(R^{n}\right)$ and $\Lambda_{\alpha}^{p}\left(R^{n}\right), 1<p<\infty$, $\alpha \cdot p \leqq n$, by $\mathfrak{B}_{\alpha, p}^{n}$ and $\mathfrak{U}_{\alpha, p}^{n}$ respectively [3]. It is well known that for $K \subset R^{n}$ : 


$$
\begin{array}{lll}
K \in \mathfrak{U}_{\alpha, p}^{n} & \text { if and only if } & A_{\alpha, p}^{n}(K)=0 \\
K \in \mathfrak{B}_{\alpha, p}^{n} & \text { if and only if } & B_{\alpha, p}^{n}(K)=0 .
\end{array}
$$

See [3].

It is interesting to note that $\mathfrak{U}_{\alpha, p}^{n}$ and $\mathfrak{B}_{\alpha, p}^{n}$ can be proved to be identical for $2-\alpha / n<p<\infty$ [1, Theorem 1] inspite of the fact that $L_{\alpha}^{p}\left(R^{n}\right) \neq \Lambda_{\alpha}^{p}\left(R^{n}\right)$ when $\alpha>0$ and $p \neq 2$ [3].

THEOREM 2. Let $\alpha>0,1<p<\infty$, and let $K$ be a compact subset of $R^{n}$. Then

$$
B_{\alpha, p}^{n}(K) \leqq c \cdot A_{\alpha, p}^{n}(K) .
$$

Constants depending on $n, p$, and $\alpha$ only, not necessarily the same at each occurance, are denoted by $c$.

REMaRK. David R. Adams [1, p. 3] has proved that $A_{\alpha, p}^{n}(K)=0$ implies $B_{\alpha, p}^{n}(K)=0$ for $\alpha>0,1<p<\infty$. Theorem 2 makes it possible to compare the capacities $B_{\alpha, p}^{n}$ and $A_{\alpha, p}^{n}$ for all sets.

It will become clear from the proofs of Theorem 1 and Theorem 2 that the restriction theorem described in $(1,1)$ and $(1,2)$ is an essential tool. (An exact formulation is given in Theorem $A$ is $\S 3$.)

At this point we just note that Theorem 2 has an alternative formulation. Under the assumptions of Theorem 2,

$$
B_{\alpha, p}^{n}(K) \leqq c \cdot B_{\beta, p}^{n+1}(K), K \subset R^{n}, \quad \beta=\alpha+\frac{1}{p} .
$$

The inclusions $L_{\alpha}^{p}\left(R^{n}\right) \subset \Lambda_{\alpha}^{p}\left(R^{n}\right)$ for $2 \leqq p<\infty$ and $\Lambda_{\alpha}^{p}\left(R^{n}\right) \subset L_{\alpha}^{p}\left(R^{n}\right)$, for $1<p \leqq 2$, are well known [3]. They give immediately the inequalities

$$
B_{\alpha, p}^{n}(K) \leqq c \cdot A_{\alpha, p}^{n}(K), \quad 1<p \leqq 2,
$$

and

$$
A_{\alpha, p}^{n}(K) \leqq c \cdot B_{\alpha, p}^{n}(K), \quad 2 \leqq p<\infty .
$$

Combining Theorem 2 with (2.1) gives,

$$
A_{\alpha, p}^{n}(K) \sim B_{\alpha, p}^{n}(K), \quad 2 \leqq p<\infty .
$$

3. Proof of Theorem 1. We first define two operators $E$ and $R$ in the following way. Let $\varphi \in C_{0}^{\infty}\left(R^{n+1}\right)$, then

$$
R \varphi(x)=\varphi(x, 0), x \in R^{n} \text {. }
$$

Let $f \in C_{0}^{\infty}\left(R^{1}\right)$ and $g \in C_{0}^{\infty}\left(R^{n}\right)$ be such that $f(0)=1$ and $\int g(x) d x=1$. 
When $\psi \in C_{0}^{\infty}\left(R^{n}\right)$ we put

$$
E \psi\left(x, x_{n+1}\right)=f\left(x_{n+1}\right) \cdot \int \psi\left(x-x_{n+1} \cdot y\right) \cdot g(y) d y,
$$

$x \in R^{n}, x_{n+1} \in R^{1}$. See for example, E. M. Stein [7].

Theorem A. Let $\alpha>0,1<p<\infty$, and $\beta=\alpha+1 / p$. Then

(a) the map $R$ is a continuous map from $L_{\beta}^{p}\left(R^{n+1}\right)\left(\Lambda_{\beta}^{p}\left(R^{n+1}\right)\right)$ to $\Lambda_{\alpha}^{p}\left(R^{n}\right)$;

(b) the map $E$ is a continuous map from $\Lambda_{\alpha}^{p}\left(R^{n}\right)$ to $L_{\beta}^{p}\left(R^{n+1}\right)\left(\Lambda_{\beta}^{p}\left(R^{n+1}\right)\right)$.

This theorem is due to E.M. Stein [7] and O.V. Besov [4]. Let $K \subset R^{n}, \alpha>0,1<p<\infty$, then

$$
B_{\beta, p}^{n+1}(K) \sim A_{\alpha, p}^{n} \sim A_{\beta, p}^{n+1}(K)
$$

where $\beta=\alpha+1 / p$.

This is an immediate consequence of Theorem $\mathrm{A}$ and the definitions of the capacities.

Proof of Theorem 1. Let $K$ be a compact subset of $R^{n}$ such that $A_{\alpha, p}^{n}(K)=0$. Let $f_{0} \in C(K)$. Since $B_{\beta, p}^{n+1}(K)=0, \beta=\alpha+1 / p$, by (3.1), there is a function $f \in L_{\beta}^{p}\left(R^{n+1}\right) \cap C\left(R^{n+1}\right)$ such that $f(x)=f_{0}(x)$ when $x \in K$ [6, Theorem 1]. Taking the restriction $R f$ we have $R f \in \Lambda_{\alpha}^{p}\left(R^{n}\right) \cap C\left(R^{n}\right)$ by Theorem A.

Conversely suppose that every $f_{0} \in C(K)$ has an extension $f \in \Lambda_{\alpha}^{p}\left(R^{n}\right) \cap C\left(R^{n}\right)$. Let $f_{0} \in C(K)$ then $E f \in L_{\beta}^{p}\left(R^{n+1}\right) \cap C\left(R^{n+1}\right), \beta=\alpha+1 / p$. By [6, Theorem 1] we must have $B_{\beta, p}^{n+1}(K)=0$, which implies $A_{\alpha, p}^{n}(K)=0$. The proof is complete.

4. Proof of Theorem 2. We begin with a lemma. Let $f \in L_{+}^{p}\left(R^{n+1}\right)$ then we define $g(y)=\left(\int f(y, t)^{p} d t\right)^{1 / p}, y \in R^{n}$.

The function $g$ belongs to $L_{+}^{p}\left(R^{n}\right)$ and

$$
\|g\|_{p}=\|f\|_{p} \text {. }
$$

(The notation $\|\cdot\|_{p}$ means that the integral defining the norm is taken over all the variables and over the whole space.)

Lemma 1. Let $\alpha>0,1<p<\infty, \beta=\alpha+1 / p$. Then for $f \in L_{+}^{p}\left(R^{n+1}\right)$,

$$
G_{\beta}^{n+1} * f(x, 0) \leqq c \cdot G_{\alpha}^{n} * g(x), \quad x \in R^{n}
$$


In the proof of Lemma 1 we use some well known properties of the Bessel kernel $G_{\alpha}^{n}(r)$ (see for example [3]):

$$
\begin{aligned}
& G_{\alpha}^{n}(r) \sim r^{\alpha-n}, r \longrightarrow 0, \text { for } 0<\alpha<n \\
& G_{\alpha}^{n}(r) \sim r^{(\alpha-n-1) / 2} \cdot e^{-r}, \quad r \longrightarrow \infty, \text { for } \alpha>0 .
\end{aligned}
$$

Proof of Lemma 1. Suppose $\alpha \cdot p \leqq n$ and let $f \in L_{+}^{p}\left(R^{n+1}\right)$ and $g(y)=\left(\int f(y, t)^{p} d t\right)^{1 / p} \cdot$ We have

$$
G_{\beta}^{n+1} * f(x, 0)=\iint G_{\beta}^{n+1}\left(\sqrt{|x-y|^{2}+t^{2}}\right) \cdot f(y, t) d y d t .
$$

For $|y-x| \leqq 1$ we get the estimate:

$$
\begin{aligned}
\int G_{\beta}^{n+1} & \left(\sqrt{|x-y|^{2}+t^{2}}\right) \cdot f(y, t) d t \leqq c \cdot \int\left(\sqrt{|x-y|^{2}+t^{2}}\right)^{\beta-n-1} \\
& \cdot f(y, t) d t \\
& =c \cdot|x-y|^{\beta-n} \cdot \int\left(\sqrt{1+t^{2}}\right)^{\beta-n-1} \cdot f(y,|x-y| \cdot t) d t \\
& \leqq c \cdot|x-y|^{\beta-n} \cdot\left(\int f(y,|x-y| \cdot t)^{p} d t\right)^{1 / p} \\
& =c \cdot|x-y|^{\beta-n-1 / p} \cdot\left(\int f(y, t)^{p} d t\right)^{1 / p} \\
& \leqq c \cdot G_{\alpha}^{n}(x-y) \cdot g(y) .
\end{aligned}
$$

For $|y-x| \geqq 1$ we get

$$
\begin{aligned}
& \int G_{\beta}^{n+1}\left(\sqrt{|x-y|^{2}+t^{2}}\right) f(y, t) d t \leqq c \cdot \int\left(\sqrt{|x-y|^{2}+t^{2}}\right)^{(\beta-n-2) / 2} \\
& \quad \cdot e^{-\sqrt{|x-y|^{2}+t^{2}}} \cdot f(y, t) d t \\
& \quad=c \cdot|x-y|^{(\beta-n) / 2} \cdot \int\left(\sqrt{\left.1+t^{2}\right)^{(\beta-n-2) / 2}} \cdot e^{-|x-y| \cdot \sqrt{1+t^{2}}}\right. \\
& \quad \cdot f(y,|x-y| \cdot t) d t .
\end{aligned}
$$

We divide the last integral in two parts

$$
I=\int_{-1}^{1} \text { and } I I=\int_{|t| \geqq 1} \text {. }
$$

Then using the inequality $\sqrt{1+x} \geqq 1+x / 3,0 \leqq x \leqq 1$ we get

$$
\begin{aligned}
& I \leqq e^{-|x-y|} \cdot \int_{-1}^{1} e^{-|x-y| \cdot t^{2} / 3} \cdot f(y,|x-y| \cdot t) d t \\
& \leqq|x-y|^{-1 / 2} \cdot e^{-|x-y|} \cdot \int e^{-t^{2} / 3} \cdot f(y, \sqrt{|x-y|} t) d t \\
& \leqq c \cdot|x-y|^{(-1-1 / p) \cdot / 2} \cdot e^{-|x-y|} \cdot g(y) .
\end{aligned}
$$


Further we have

$$
\begin{aligned}
I I & \leqq e^{-\sqrt{2} \cdot|x-y|} \cdot \int\left(\sqrt{1+t^{2}}\right)^{(\beta-n-2) / 2} \cdot f(y,|x-y| \cdot t) d t \\
& \leqq c \cdot e^{-\sqrt{2} \cdot|x-y|} \cdot|x-y|^{-1 / p} \cdot g(y) .
\end{aligned}
$$

Collecting our results we have

$$
\int G_{\beta}^{n+1}\left(\sqrt{|x-y|^{2}+t^{2}}\right) \cdot f(y, t) d t \leqq c \cdot G_{\alpha}^{n}(x-y) \cdot g(y)
$$

which gives

$$
G_{\beta}^{n+1} * f(x, 0) \leqq c \cdot G_{\alpha}^{n} * g(x),
$$

where $\beta=\alpha+1 / p$.

The case $\alpha \cdot p>n$ is much simpler and the proof is omitted.

Proof of Theorem 2. According to the relation (3.1) it suffices to prove that for every $f \in L_{+}^{p}\left(R^{n+1}\right)$ such that $G_{\beta}^{n+1} * f(x, 0) \geqq 1$ for $x \in K$, there exists $g \in L_{+}^{p}\left(R^{n}\right)$ such that $G_{\alpha}^{n} * g(x) \geqq 1$ for $x \in K$ and

$$
\|g\|_{p} \leqq c \cdot\|f\|_{p} \cdot
$$

But this follows immediately from Lemma 1. This proves the theorem.

\section{REFERENCES}

1. David R. Adams, On the exceptional sets for spaces of potentials, Pacific J. Math., 52 (1974), 1-5.

2. David R. Adams and John C. Polking, The equivalence of two definitions of capacity, Proc. Amer. Math. Soc., 37:2 (1973), 529-534.

3. N. Aronszajn, F. Mulla and P. Szeptycki, On spaces of potentials connected with $L^{p}$-classes, Ann. Inst. Fourier, 13 (1963), 211-306.

4. O. V. Besov, On a certain family of functional spaces. Imbedding and continuation theorem, Dokl. Akad. Nauk., 126 No. 6 (1959), 1163-1165.

5. N. G. Meyers, A theory of capacities for potentials of functions in Lebesgue classes, Math. Scand., 26 (1970), 255-292.

6. T. Sjödin, Bessel potentials and extension of continuous functions on compact sets, Ark. Mat., 13 (1975), 263-271.

7. E. M. Stein, The characterization of functions arising as potentials $I$, Bull. Amer. Math. Soc., 67 (1961), 102-104. II (ibid.), 68 (1962), 577-582.

Received October 8, 1976.

UNIVERSITY OF UMEA

SWEDEN 


\section{PACIFIC JOURNAL OF MATHEMATICS}

\section{EDITORS}

RICHARD ARENS (Managing Editor)

University of California

Los Angeles, California 90024

C. W. CurTis

University of Oregon

Eugene, OR 97403

C. C. MOORE

University of California

Berkeley, CA 94720
J. DUGUNDJI

Department of Mathematics University of Southern California Los Angeles, California 90007

R. FinN AND J. Milgram Stanford University Stanford, California 94305

\section{ASSOCIATE EDITORS}

E. F. BECKENBACH

B. H. NeumanN

F. WOLF

K. YoSHIDA

\section{SUPPORTING INSTITUTIONS}

UNIVERSITY OF BRITISH COLUMBIA CALIFORNIA INSTITUTE OF TECHNOLOGY UNIVERSITY OF CALIFORNIA MONTANA STATE UNIVERSITY UNIVERSITY OF NEVADA, RENO NEW MEXICO STATE UNIVERSITY OREGON STATE UNIVERSITY UNIVERSITY OF OREGON
UNIVERSITY OF SOUTHERN CALIFORNIA

STANFORD UNIVERSITY

UNIVERSITY OF HAWAII

UNIVERSITY OF TOKYO

UNIVERSITY OF UTAH

WASHINGTON STATE UNIVERSITY

UNIVERSITY OF WASHINGTON 


\section{Pacific Journal of Mathematics \\ Vol. 78, No. $1 \quad$ March, 1978}

Simeon M. Berman, A class of isotropic distributions in $\mathbf{R}^{n}$ and their

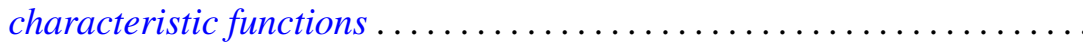

Ezra Brown and Charles John Parry, The 2-class group of biquadratic fields.

II ........................................ 11

Thomas E. Cecil and Patrick J. Ryan, Focal sets of submanifolds ....... 27

Joseph A. Cima and James Warren Roberts, Denting points in $B^{p} \ldots \ldots \ldots 41$

Thomas W. Cusick, Integer multiples of periodic continued fractions . . . . . 47

Robert D. Davis, The factors of the ramification sequence of a class of

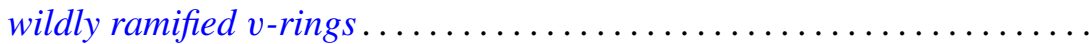

Robert Martin Ephraim, Multiplicative linear functionals of Stein

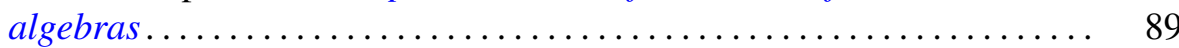

Philip Joel Feinsilver, Operator calculus . .................... 95

David Andrew Gay and William Yslas Vélez, On the degree of the splitting field of an irreducible binomial ..........................

Robert William Gilmer, Jr. and William James Heinzer, On the divisors of

monic polynomials over a commutative ring ..................

Robert E. Hartwig, Schur's theorem and the Drazin inverse .............

Hugh M. Hilden, Embeddings and branched covering spaces for three and four dimensional manifolds ............................

Carlos Moreno, The Petersson inner product and the residue of an Euler product. ...

Christopher Lloyd Morgan, On relations for representations of finite groups....

Ira J. Papick, Finite type extensions and coherence

$\mathrm{R}$. Michael Range, The Carathéodory metric and holomorphic maps on a class of weakly pseudoconvex domains ................

Donald Michael Redmond, Mean value theorems for a class of Dirichlet series

Daniel Reich, Partitioning integers using a finitely generated semigroup ...

Georg Johann Rieger, Remark on a paper of Stux concerning squarefree

numbers in non-linear sequences

Gerhard Rosenberger, Alternierende Produkte in freien Gruppen ..

Ryōtarō Satō, Contraction semigroups in Lebesgue space

Tord Sjödin, Capacities of compact sets in linear subspaces of $\mathbf{R}^{n}$

Robert Jeffrey Zimmer, Uniform subgroups and ergodic actions of exponential Lie groups......................... 